\title{
1. Introduction to Planned Urban Development
}

This book is about planned urban development. It considers and reflects upon the programme of planned urban expansion that took place in England between the early 1950s and late 1970s. In a period of rapidly rising population and urban renewal, the Town Development Act (1952) empowered conurbation authorities and those in smaller towns to negotiate programmes for the planned expansion of the latter to accommodate overspill populations from the former. This rather obscure and almost forgotten legislation had a significant effect upon the pattern of urban development in this country and a study of its implementation and contribution may yet offer important lessons in tackling today's urban planning agenda.

The population of most western European countries is expected to grow substantially in the coming years. According to the European Union the population of the United Kingdom (UK) is projected to grow by 10.3 per cent between 2015 and 2030, Ireland by 11.2 per cent, France by 6.2 per cent and the Netherlands by 8.8 per cent. Even Germany, where population has stagnated for so long, is likely to see growth of 4.2 per cent (Eurostat, 2019). In total the population of these countries is projected to grow by around 17 million people over the period. At an assumed average household size of 2.3 pph (persons per household) this equates to a need for an additional 7.4 million dwellings, including perhaps as many as 2.8 million in the UK.

The question arises: where and in what form should these dwellings be built? The conventional wisdom of sustainable urban development has long called for more compact cities and an increase in urban densities. There are strong reasons to support this view: European economies and societies are increasingly urban and compact cities can reduce the demand for travel and energy use and limit urban sprawl. On the other hand, it is important to maintain decent and healthy living conditions and humane urban environments. There is growing evidence to suggest that in many cities pressures to increase the number and density of dwellings has led to some disregard for housing standards and the quality of the urban environment. Many, including the Town and Country Planning Association, have argued strongly for an alternative and better planned approach to the problem based around the concept of garden cities and new towns (Henderson et al., 2017). Indeed, since the Coronavirus 
crisis of 2020 it is now even more important to consider the relationship between urban form and public health. So what is the best way forward: increasing the density of existing cities or developing planned new towns? Or is there another alternative based upon the expansion of smaller existing towns?

In the post-war era the UK and some other European countries established programmes for the building of planned new towns to provide housing around conurbations or to act as growth-poles for regional development. Less well known but of equal significance in terms of the scale of development were the town expansion schemes (the planned growth of smaller existing towns) designed to accommodate overspill populations from the conurbations or, in some cases, to accommodate locally generated growth. While much has been written about the contribution of the new towns, there has been relatively little discussion of town expansion schemes. This book attempts to redress that balance by considering the purposes, nature, contribution and problems of planned town expansion schemes.

There is, of course, already a substantial body of planning theory to inform policy makers and professional practice. This theory is commonly divided into: (i) theories of planning, which are concerned with planning procedures and methods and processes of decision making, i.e. how plans are made; and (ii) theories in planning, concerning the substantive content of plans and designs, i.e. what planners are trying to achieve (Faludi, 1973). While this distinction is, in reality, rather blurred with considerable interaction and overlap between the processes and aims of planning, this book is mainly an attempt to contribute to theories in planning. In so doing, this book focuses on three questions:

- what was the nature of the expanded towns programme and what did it achieve?

- what lessons might be learned from the programme?

- is there a case for further planned expansion of smaller towns today?

Strongly influenced by the garden cities movement, one of the most significant statements of theory in planning was contained in Patrick Abercrombie's 1933 book, Town and Country Planning. The goal, he argued, was to achieve 'beauty, health and convenience' in the design and layout of the city. Applying Abercrombie's views to modern life it can be said that planning today is about achieving aesthetically attractive places, healthy and sustainable environments and efficient patterns of urbanisation at both regional and local levels. The subsequent wartime and post-war periods generated considerable debate and advances for theories in planning. The Barlow Report (1940) had set out a broad regional and urban planning agenda and new planning legislation was passed in the late 1940s. Influential books were published, including 
Mumford's The Culture of Cities (1938) and Keeble's Principles and Practice of Town and Country Planning (1952) and the government used key academics and planning consultants such as Thomas Sharp and Frederick Gibberd to help draft official planning guidance. High on the planning agenda in this period were the need to tackle regional economic imbalance, modernise urban areas, reduce densities, eliminate slum housing and control the problem of urban sprawl.

Urban sprawl was a major theoretical and practical concern to planners in the post-war period. Urban sprawl is a reduction in the angle of the urban density gradient that causes a town or city to spread over an ever larger area of land (Couch, 2016). It can be seen as 'the gluttonous use of land, uninterrupted monotonous development, leapfrog discontinuous development and inefficient use of land' (Peiser, 2001, p. 278), or as a pattern of urbanisation that 'exhibits low levels of some combination of eight distinct dimensions: density, continuity, concentration, clustering, centrality, nuclearity, mixed uses, and proximity' (Galster et al., 2001, p. 685).

Urban sprawl leads to the unnecessary loss of productive agricultural land and the fragmentation of natural habitats. Compared with more compact urban forms, urban sprawl is associated with higher levels of energy consumption, especially in relation to transport systems. More intra-urban journeys are made by car and the distances travelled are frequently longer (to work, school, shops, health services and leisure activities). Public transport is more difficult to provide and the greater distances also discourage walking and cycling. There is more spatial social segregation. Utility and municipal services as well as retail and commercial facilities are more costly. For all these reasons planners consistently looked for the most efficient forms of urbanisation (Couch, 2016).

The legal mechanisms to support the planning of new urban areas to accommodate overspill population from the conurbations as a means of controlling urban sprawl was first enshrined in British legislation in the New Towns Act (NTA) (1946) and the Town Development Act (TDA) (1952). But the legislation embodied ideas of controlling urban sprawl and the unplanned growth of the conurbations that had been discussed over the previous decades and elaborated in wartime plans such as the Greater London Plan (1944) and similar plans for other conurbations (Cullingworth, 1979; Ward, 2004; Hall and Tewdwr-Jones, 2011).

This study is mainly focussed upon expanded towns in England, most of which were established under the TDA (1952). There was a related programme in Scotland but it was different in nature and is not part of this study. There were no equivalent programmes in Wales or Northern Ireland. Towards the end of the book some comparisons are made with similar programmes in the Netherlands and France in order to identify which characteristics and experi- 
ences are endemic to this type of urbanisation and which issues are country- or place-specific.

Most of the town expansion schemes in England were initiated in the 1950s and 1960s. They were established mainly as an alternative to the new towns as a means of accommodating overspill population from overcrowded cities. The thinking was that the planned expansion of existing towns offered two advantages over the new towns programme:

- they could use and build upon existing infrastructure and therefore be less costly and provide a better range of services and amenities than was the case in completely new towns;

- they were more accountable to local democratic control than the centrally planned new towns.

The process was that large cities could enter into an agreement with a receiving authority where dwellings would be built and employment provided to support an incoming overspill population. Schemes were supported financially by grants from central government and contributions from the exporting authority. The great majority of schemes were to support overspill from London to smaller towns in the surrounding region, although other major cities, such as Birmingham and Liverpool, also established overspill agreements with nearby towns.

Through the post-war decades there was considerable academic and professional debate about the relative merits of these town expansion schemes compared with the new towns programme. There were also a number of general discussions and evaluations of the new towns programme and town expansion schemes, notably Seeley's Planned Expansion of Country Towns (1968), Schaffer's The New Town Story (1970), Osborn and Whittick's New Towns: Their Origins, Achievements and Progress (1977) and Cullingworth's 'official' history published by HMSO: Environmental Planning 1939-1969, Volume III: New Towns Policy (1979). A number of local case histories and evaluations were also published. Harloe's Swindon: A Town in Transition (1975) and Butler's The Dream Fulfilled: Basingstoke Town Development, 1961-1978 (1980) are good examples.

Recently there has been some renewed interest in new towns. It has been a theme strongly promoted by the Town and Country Planning Association as well as being the subject of a number of recent books including: Alexander's Britain's New Towns: Garden Cities to Sustainable Communities (2009), Gaborit's European New Towns: Image, Identities, Future Perspectives (2010), Ward's Peaceful Path: Building Garden Cities and New Towns (2016), and Henderson et al.'s The Art of Building a Garden City (2017). But little has been heard about the possible contribution of town expansion schemes to the 
contemporary planning problem of accommodating an expanding population in sustainable communities.

This book therefore provides an account of the experience of expanded towns policy in England from its inception to the present day. Evidence is drawn from a number of case study towns before discussing key questions and concluding on the achievements and lessons to be learned from the programme. Before looking at the case studies, there are two general chapters. Chapter 2 considers the emergence of the modern planning system from its mid-19th-century public health origins; the appearance of problems of congestion, sprawl and uneven regional development in the inter-war period; post-war policy responses and plans; the emergence of expanded towns policy and the Town Development Act (1952); progress with the implementation of town expansion in the 1950s; accelerating activity in the 1960s; and then the changing priorities of the 1970s which led to the demise of the programme.

The geography and planning of expanded towns is explored in Chapter 3, including their location, scale, characteristics and design. There were more than 60 expanded towns across England, about half providing for London overspill and the remainder for provincial conurbations. The choice and location of expanded towns was determined through negotiation between the exporting and receiving authorities, albeit to some extent influenced by the views of central government and the county councils. Having agreed a target population, which might vary from an additional 2,000 to 30,000 or more people, the required amount of dwellings, industrial land, schools, shops, civic and cultural amenities and public open space would then be calculated. A Master Plan would be drawn up to show the disposition of land uses and the circulation system. Implementation would be the responsibility of the receiving authority, although depending upon the scale of the programme and local circumstances, there might be some form of joint development arrangements with inputs from the county council and the exporting authority. Residential areas were usually planned on the 'neighbourhood principle' focussed upon a local centre and primary school. Traffic planning and the segregation of pedestrian and vehicular movements were frequently important considerations in these plans. Another aim was to achieve a high degree of self-containment in the expanded towns, principally by keeping employment and population growth in balance. This proved to be exceptionally difficult with employment growth subject to the vagaries of the macro-economy as well as local geographic circumstances.

Beyond this general discussion the book then moves on to a series of chapters that provide a comparative examination of different types of expanded towns. Chapter 4 looks at Bletchley and Swindon, two towns that were amongst the first to grasp the advantages offered by planned expansion. In the small town of Bletchley expansion was seen as a chance to improve the employment 
opportunities and amenities available to local people. For Swindon expansion was an opportunity to diversify the economy in the face of uncertainties surrounding the future of the railway works. In both cases specific local political leaders played a key role in driving forward the expansion programmes. Both towns were successful in their ambitions for expansion, each attracting large volumes of new employment and population from London and elsewhere. The Bletchley location proved such an attractive location for regional growth that it was included in the designated area of Milton Keynes new town in 1968. The area continued to expand and was identified by government as a suitable location for yet further growth in 2003 and again more recently by the post-2010 Coalition Government. Swindon too proved to be a successful location and has continued to expand but more organically than Milton Keynes. It too has also been earmarked by the government as a growth zone and is likely to continue expanding into the future.

Chapter 5 looks at other expanded towns serving London, including Haverhill, Banbury, Basingstoke, Andover and Thetford. In the 1950s many East Anglian towns, such as Haverhill and Thetford, were seen as remote, poorly equipped and in serious economic decline with few resources to change their circumstances. Expansion, mainly funded by the government and London County Council (LCC) offered the chance of a brighter future. For the larger town of Banbury in Oxfordshire the position was slightly different; it had a long history as a market town, had already seen the arrival of new industrial jobs in the 1930s and overspill agreements with London and Birmingham would simply add to an increasingly mixed local economy. In Hampshire the situation was different again. Here the County Council negotiated with the Borough Councils of Basingstoke and Andover to accept town expansion as a means of forestalling an LCC proposal to build a new town in the county.

Chapter 6, 'Planning for overspill in North-West England', reports on the experience of expansions at Ellesmere Port and Winsford in very different economic circumstances from those prevailing in the South-East. In both towns large-scale expansions were proposed to provide overspill accommodation for Manchester (Winsford) and Liverpool (Ellesmere Port and Winsford). The scale of expansion came to dominate and permanently change the characters of the two towns. In both cases population was to double in little over a decade. While growth in Ellesmere Port depended upon a relatively small number of large employers in oil refining, petro-chemicals and the motor industry, Winsford was more reliant upon attracting small and medium-sized firms, particularly in manufacturing, engineering and logistics. Both suffered economic setbacks in the 1980s that left residual problems of urban deprivation. But both have recovered well and are evolving into more rounded communities with new housing being built and new investment in infrastructure and employment. 
Chapter 7 discusses the use of the New Towns Acts (NTA) to implement larger expansion schemes. By the late 1960s the government had come to the view that in many circumstances expansion offered better value for money than new towns and that larger town schemes offer useful economies of scale, but it was also clear that the NTA was administratively superior to arrangements under the TDA. This led to the proposal that a number of new larger town expansion schemes should be implemented by means of the NTA, including those at Northampton and Warrington.

Chapter 8 looks at experiences from the Netherlands and France. One important difference between these two countries and England is in the location of town expansion schemes. In the Netherlands and in France, the schemes are invariably seen as extensions to or close by the conurbations for which they are to provide overspill. As Tuppen mentions in relation to Paris, these towns are seen as complementary to the existing urban area and contribute to its reshaping (Tuppen, 1979). The British town expansion schemes, particularly those serving London, were located much further away and seen as a counterbalance to the pull of the conurbation. In both countries the public sector appears to exercise a higher level of control over the planning and development process with greater emphasis on producing quality urban and architectural design than has been experienced in England, perhaps with the exception of the early phases of new town development.

Following these case-based explorations Chapter 9 draws on the findings of the empirical work to discuss a number of key issues including: the reasons and justifications for town expansion schemes; the scale of development and relationship with the existing town; overall planning characteristics, design and architecture; issues of governance, ownership and planning processes; development and change over time and responses to change; successes, failures and lessons; future prospects and possibilities for planned urban development.

A concluding chapter then summarises and discusses the nature of the programme of planned town expansion and what it achieved, the lessons that might be learned and the case for further planned expansion of smaller towns today, particularly in a world where Coronavirus may have become endemic. 